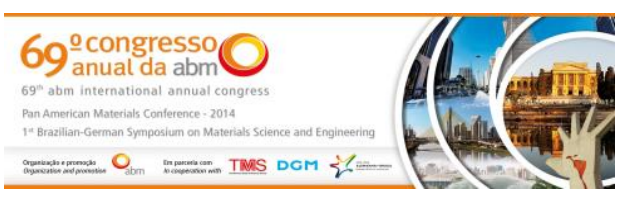

Tema: Produtos Metálicos não-ferrosos

\title{
APLICAÇÃO DE POLITETRAFLUORETILENO EM LIGAS DE ALUMÍNIO*
}

Jorge Luis Braz Medeiros ${ }^{1}$ Afonso Reguly ${ }^{2}$

Telmo Roberto Strohacker ${ }^{2}$

\section{Resumo}

As ligas de Alumínio ASTM 2014, caracterizam-se por apresentarem elevada resistência mecânica, quando comparadas a demais ligas de Alumínio. Este comportamento está associado ao tratamento térmico de Solubilização e envelhecimento, sendo que no envelhecimento artificial existem diferentes curvas de avaliação do limite de resistência, limite de escoamento, alongamento etc. Neste trabalho serão apresentados os efeitos da cura de revestimento de Politetrafluoretileno, realizado a $230^{\circ} \mathrm{C}$, nas propriedades mecânicas e na dureza, destas ligas, após a condição preliminar de solubilização. O Politetrafluoretileno confere baixo coeficiente de atrito e acabamento diferenciado, sendo comparado seu efeito com processos de anodização.

Palavras-chaves: Alumínio; Politetrafluoretileno; Resistência mecânica.

\section{APPLICATION OF POLYTETRAFLUOROETHYLENE IN ALUMINUM ALLOYS}

\begin{abstract}
Aluminum Alloys ASTM 2014 are characterized by presenting high mechanical strength, when compared to other aluminum alloys. This behavior is associated with the heat treatment of Solubilization and aging, and the artificial aging curves are different for evaluation of tensile strength, yield strength, elongation etc. In this work the effects of curing coating Politetraflueretileno held at $230^{\circ} \mathrm{C}$, the mechanical properties and hardness, these alloys after preliminary condition of solubilization and aging will be presented. Polytetrafluoroethylene gives low friction and distinctive finish, and compared its effect with anodizing processes.
\end{abstract}

Keywords: Aluminum; Polytetrafluoroethylene; Mechanical resistance.

1 Doutorando, MSc. Eng. Metalúrgico, Programa de Pós Graduação em Engenharia de Minas, Metalúrgica e de Materiais (PPGEM), UFRGS, Porto Alegre, RS, Brasil.

2 Professor Dr., Programa de Pós Graduação em Engenharia de Minas, Metalúrgica e de Materiais (PPGEM) UFRGS, Porto Alegre, RS, Brasil. 


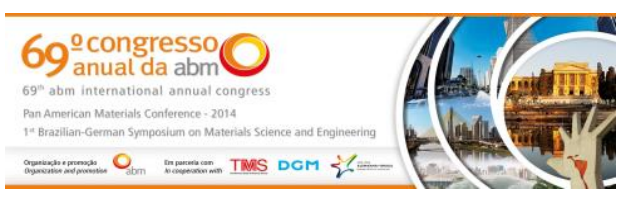

\section{INTRODUÇÃO}

Nas últimas décadas, o setor metal mecânicos, mais especificamente às áreas de fabricação de alumínio, tem apresentado, inovações significativas. Estas inovações podem ser verificadas, desde o desenvolvimento de novas ligas, melhorias nos processos e melhoras no desempenho destes materiais.

Entre as ligas de Alumínio podemos destacar as ligas de elevada resistência ASTM 2014 solubilizadas e envelhecidas artificialmente (T6).

Estas ligas apresentam curvas de envelhecimento definidas e associadas as propriedades mecânicas destes materiais. O alumínio, apresenta entre outras propriedades elevada resistência a corrosão, originada desde a camada de alumina na superfície. Este desempenho acentua-se quando da aplicação de processo de anodização, porém sua resistência à corrosão pode ser diminuída com a adição de elemento de liga.

A aplicação superficial de Politetrafluoretileno (Teflon) pode ser classificada como uma alternativa dentro da engenharia de superfície, para o aumento da resistência a corrosão, diminuição do coeficiente de atrito, bom acabamento superficial entre outros. As temperaturas de cura, após a aplicação deste revestimento são muito próximas as de envelhecimento artificial, das ligas de alumínio. A partir destes parâmetros, avaliou-se que em algumas aplicações exista a possibilidade da conjugação de diferentes materiais, com aço de baixa resistência à corrosão e alumínio.

Neste trabalho desenvolveu-se processo de cura do revestimento Politetraflueretileno, associando-se temperatura de cura, com curvas de envelhecimento, conferindo homogeneidade de acabamento, resistência a corrosão e razoável valor de limite de resistência do conjugado.

\section{MATERIAIS E MÉTODOS}

\subsection{Composição Química}

Foram realizadas análises químicas em duas amostras de Alumínio, com composição química adequada a obtenção de valores de elevada resistência mecânica, para alumínios solubilizados e envelhecidos. O Método utilizado foi espectrometria por emissão óptica. Na figura 1 abaixo, verifica-se o equipamento utilizado. 

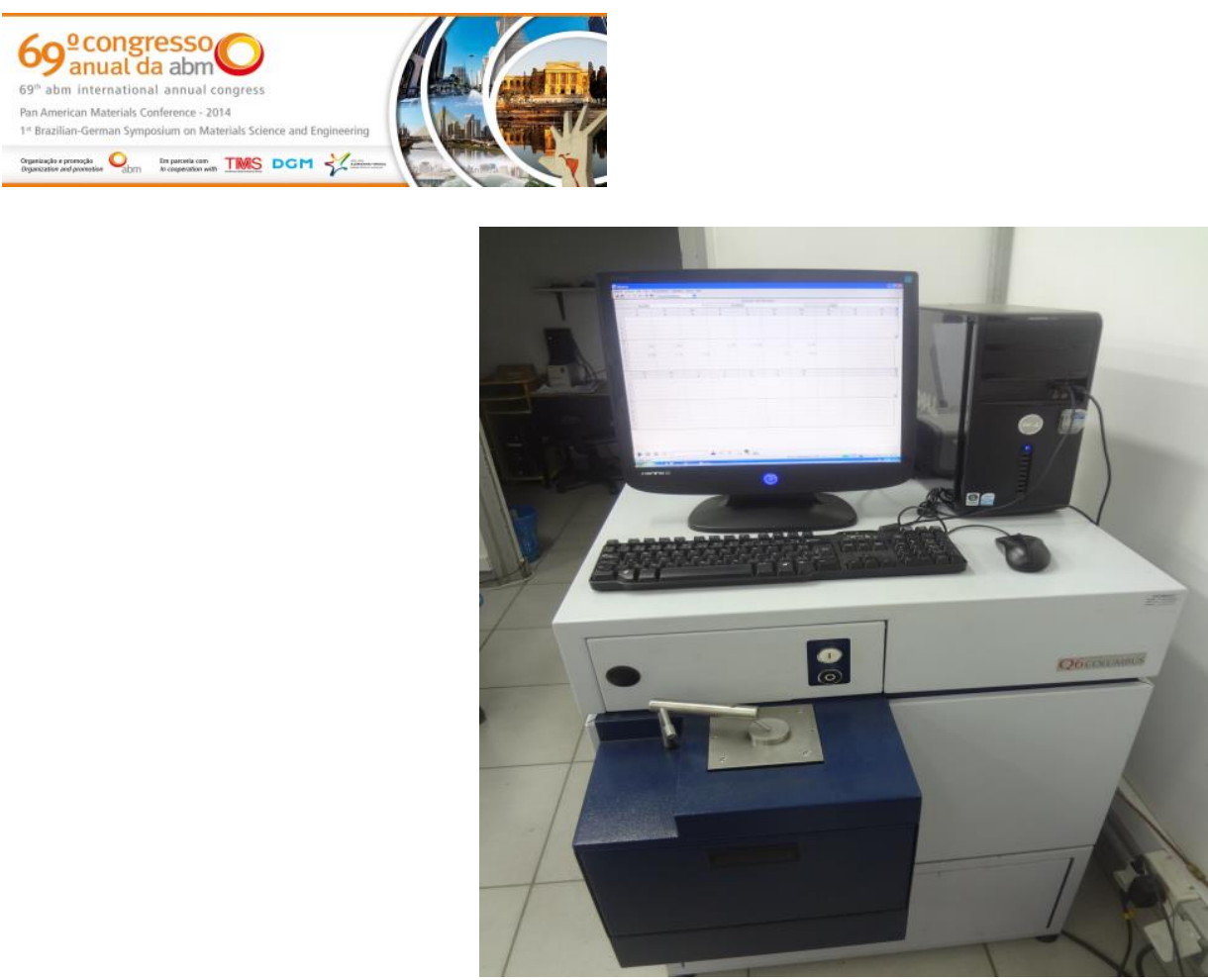

Figura 1 - As análises, foram realizadas, em um espectrômetro de emissão óptica, modelo Q6 Columbus, marca Bruker Quantron.

\subsection{Solubilização das Ligas de Alumínio}

As ligas de Alumínio foram solubilizadas, seguindo os procedimentos normais indicados na literatura, quanto à temperatura e tempo de homogeneização. $O$ tratamento térmico realizado em fornos com recirculação originando homogeneização de temperaturas, por convecção.

\subsection{Aplicação do Filme de Politetrafluoretileno}

As amostras foram preparadas para a aplicação de filme de Politetrafluoretileno com a utilização de pistolas pressurizadas.

Aplicou-se filme de politetraflueretileno sobre as amostras com uma espessura de aproximadamente $50 \mu \mathrm{m}$, verificando-se a espessura em software de análise de imagens.

\subsection{Tratamento de Envelhecimento e Secagem do Filme de Politetrafluoretileno}

Utilizando-se dados da literatura, verificaram-se as temperaturas e tempos que pudessem associar à resistência das ligas Alumínio ASTM 2014, com a temperatura de secagem do filme de Politerafluoretileno. A figura 2 abaixo indica as curvas típicas de envelhecimento da liga de alumínio ASTM 2014. 

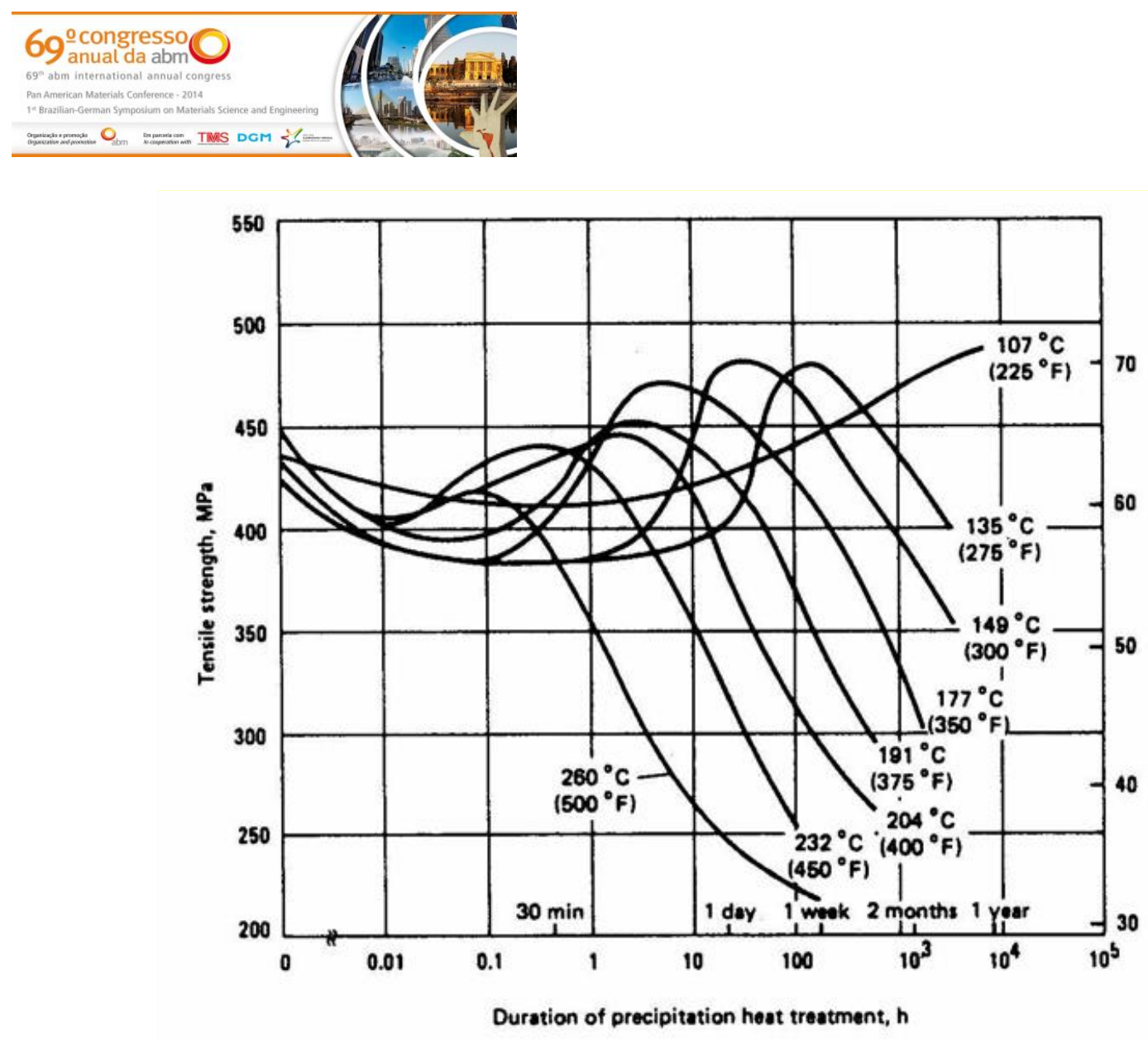

Figura 2 - Curvas de envelhecimento do Alumínio associando temperatura e limite de resistência.

Com ensaios de dureza Brinell, determinou-se a melhor temperatura associada à dureza e mais elevada resistência mecânica encontrada nas ligas estudadas.

\section{RESULTADOS E DISCUSSÃO}

\subsection{Composição Química}

$\mathrm{Na}$ tabela 1, podem ser verificadas as composições químicas das amostras analisadas, sendo, caracterizadas como ligas de Alumínio de alta resistência, classe ASTM 2014.

Tabela 1 - Composição química, das amostras analisadas.

\begin{tabular}{|l|l|l|l|l|l|l|l|l|l|}
\hline Amostra & $\% \mathrm{Si}$ & $\% \mathrm{Fe}$ & $\% \mathrm{Cu}$ & $\% \mathrm{Mn}$ & $\% \mathrm{Mg}$ & $\% \mathrm{Cr}$ & $\% \mathrm{Ni}$ & $\% \mathrm{Zn}$ & $\% \mathrm{Ti}$ \\
\hline Lote 1 & 0,04 & 0,221 & 4,2 & 0,7 & 0,4 & 0,01 & 0,01 & 0,02 & 0.037 \\
\hline Lote 2 & 0,04 & 0,296 & 4,2 & 0,7 & 0,3 & 0,01 & 0,0035 & 5,40 & 0,021 \\
\hline
\end{tabular}

\subsection{Solubilização das Ligas de Alumínio}

As amostras foram solubilizadas, com objetivo de obter-se intermetálicos distribuídos para posterior precipitação. Esta etapa preliminar, ao processo de aplicação de Politetrafluoretileno e envelhecimento artificial (cura) é fundamental, sendo- que não foram detectadas variações significativas de temperatura ou tempo. 


\subsection{Aplicação do Filme de Politetrafluoretileno}

A aplicação do filme de Politetrafluoretileno foi realizada através de pintura com pistola pressurizada, com espessura de $57,39 \mu \mathrm{m}$, conforme verificado na figura 3 abaixo.

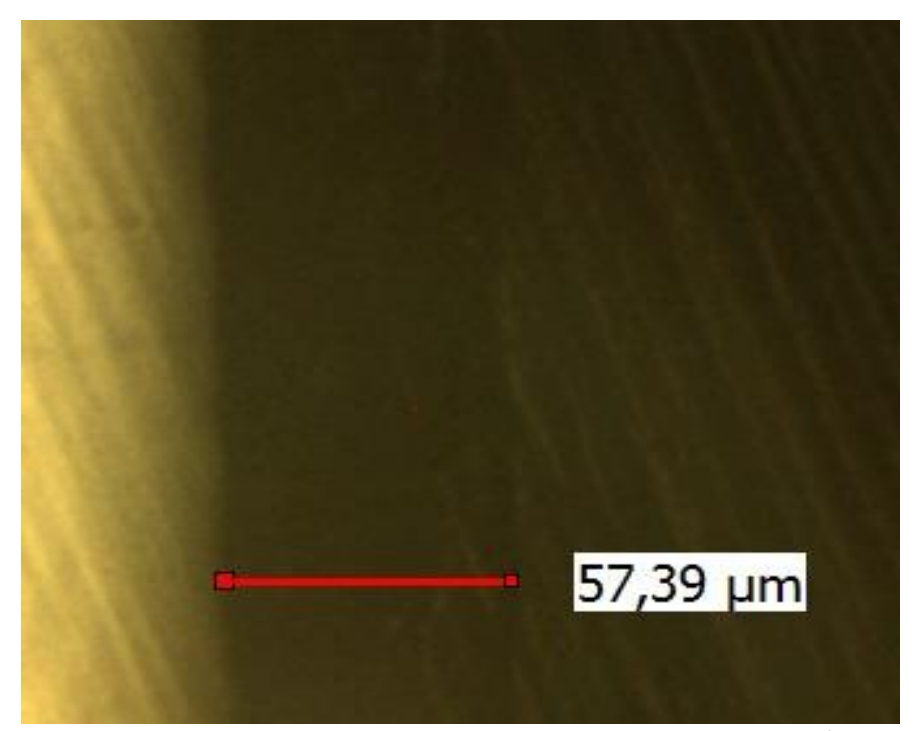

Figura 3 - Detecção da espessura de camada de Politetrafluoretileno.

\subsection{Tratamento de Envelhecimento e Secagem do Filme de Politetrafluoretileno}

A Temperatura de envelhecimento (secagem) que apresentou melhores resultados foi de $230^{\circ} \mathrm{C}$, onde o resultado foi de $430 \mathrm{MPa}$ e dureza de $126 \mathrm{HB}$.

Nas demais temperaturas houve uma redução da resistência mecânica e dureza, pois se afastaram do pico de máxima resistência desta liga ou ficaram fora da faixa de temperaturas de cura do Politetrafluretileno. Na figura 4 abaixo, placas segregadas em regiões isoladas do substrato, após tratamento térmico de envelhecimento.

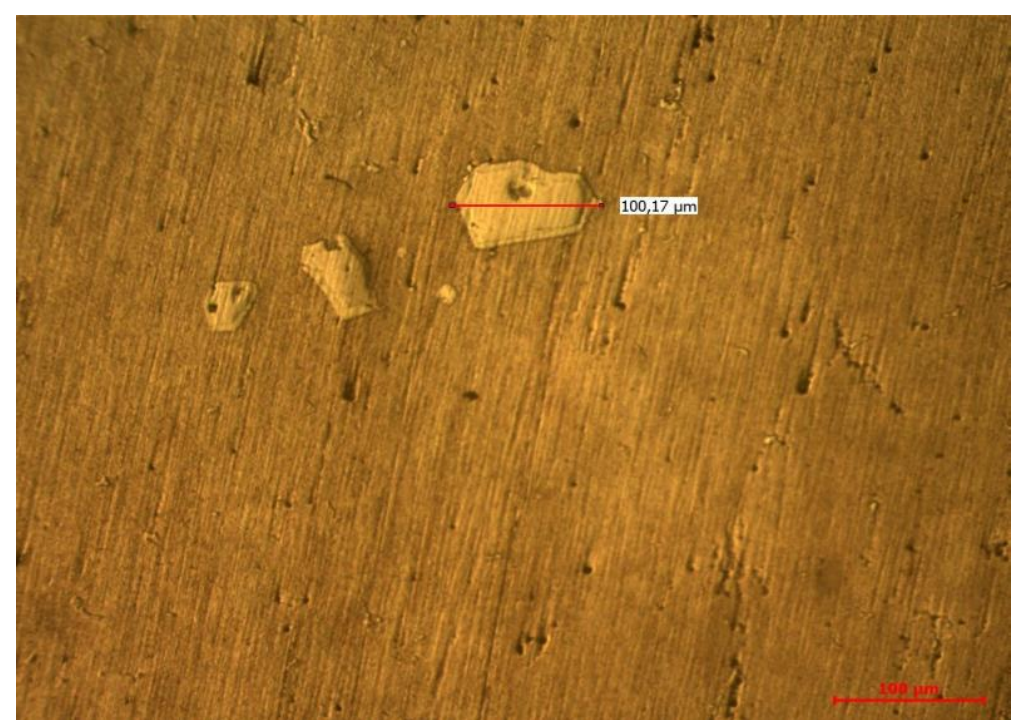

Figura 4 - Placas segregadas na microestrutura oriundas por superaquecimento na conformação mecânica. 


\section{CONCLUSÕES}

Conclui-se que existe compatibilidade entre as temperaturas de envelhecimento do Alumínio e de cura após a aplicação de filme de politetrafluoretileno. Porém as pigmentações a serem utilizadas apresentaram melhor desempenho, quando apresentavam base água, por apresentarem possibilidades de serem secadas a temperaturas mais baixas.

A microestrutura final apresentou-se homogênea, porém com detecção de plaqueta com crescimento anormal.

Nos ensaios de adesão, não houve desplacamento significativo, indicando boa aderência do filme sobre o substrato.

Temperaturas mais elevadas de cura, do filme de Politetrafluoretileno, não foram eficientes, quanto à manutenção da resistência mecânica da liga ASTM 2014, em patamares elevados.

Foram alcançados os objetivos de solubilizar a liga de alumínio em estudo, aplicar filme de politetrafluoretileno, realizar cura e envelhecimento de forma simultânea alcançando boa resistência mecânica. Desta forma foi possível o aumento da resistência à corrosão de materiais conjugado, como aço baixa liga e alumínio, sem comprometer as propriedades mecânicas de ambos.

\section{BIBLIOGRAFIA}

1 ASM. Metals Handbook - Heat Treating. vol.4. ASM; 1991.

2 Associação Brasileira do Alumínio. Disponível em: http://www.abal.org.br .

3 ASM. Metals Handbook - Metallography and Microstructure. vol.9. ASM;1985.

4 ASTM. Standard Practice for Heat Treatment of Aluminum. ASTM 2001. 